\title{
Bleeding characteristics and management of minor surgeries in rare bleeding disorders: report from a Turkish Pediatric Hematology Center
}

\author{
Sema Aylan Gelen ${ }^{\oplus}$ Nazan Sarper ${ }^{\ominus}$, Emine Zengin ${ }^{\bullet}$ \\ Division of Pediatric Hematology, Department of Pediatric, Kocaeli University Faculty of Medicine, Kocaeli, Turkey.
}

\begin{abstract}
Background and objectives. In this retrospective report the aim was to present the experience about bleeding characteristics and management of minor surgeries in rare bleeding disorders (RBDs).

Methods. Twenty-six patients were included; with Factor (F) V, FV+VIII, VII, FXI deficiency and afibrinogenemia. Six of the patients were asymptomatic.

Results. Fifty-three percent of the patients suffered from mucosal bleeding. Life-threatening bleedings were observed only in the patients with afibrinogenemia and good hemostatic control could only be provided with plasma-derived (pd)-fibrinogen concentrate. Twelve of the patients had undergone 17 minor surgeries. In the patients with FVII and FXI deficiencies with plasma F:C activity between 20-47\%, there was a history of uneventful tooth extractions, circumcisions and a pilonidal sinus operation performed without any replacement treatment, whereas one patient with plasma F:C activity of FVII $47 \%$ had a history of poor hemostatic control during an adeno-tonsillectomy operation. Although some of these patients were asymptomatic to be on the safe side, minor operations were performed with preoperative administration of one dose of (pd)-fibrinogen concentrate to one afibrinogenemia patient, recombinant active FVII ( $\mathrm{rFVIIa}$ ) to $2 \mathrm{FVII}$ deficient patients and fresh frozen plasma (FFP) to 3 FXI deficient and 1 FVII deficient patients plus postoperatively tranexamic acid (TXA) for 5-7 days. Only with one dose of the replacement therapy just before surgeries good hemostatic control was achieved and none of them had bleeding neither during nor after the surgeries.
\end{abstract}

Conclusion. We suggest that minor operations must be performed with preoperative replacement therapies plus 5-7 days of antifibrinolytics under close observation of the hematologist and the surgeon.

Key words: blood coagulation disorders, rare diseases, minor surgical procedures.

Rare bleeding disorders including factor (F) II, FV, combined FV and FVIII, FVII, FX, FXI, FXIII, and fibrinogen deficiencies represent $3-5 \%$ of all inherited coagulation deficiencies. ${ }^{1-3}$ In addition to rarity of these deficiencies, the severity of the bleeding symptoms is heterogenous. Patients may suffer from mucocutaneous bleeding, but more severe bleeding like gastrointestinal (GIS) bleeding, central nervous system (CNS)

Sema Aylan Gelen

semaylan@hotmail.com

Received 14th February 2019, revised 3rd May 2019, 9th June 2019, 22nd August 2019, 29th October 2019; accepted 25th December 2019. bleeding, post-traumatic hemarthrosis and hematomas, or umbilical cord bleeding may be observed. Some patients are asymptomatic, but they may present with surgical or invasive procedure-associated bleeding.,4 Management of surgery is based on experience from case reports. ${ }^{5}$ Bleeding history of the patient or family may determine the severity of the disorder. Plasma F:C activity is not always correlated with bleeding severity. ${ }^{6}$

Asymptomatic patients or patients with mild symptoms undergoing minor surgery are a dilemma for hematologists although there are some reports and guidelines about management of bleeding episodes and minor surgery. $3,5,7,8$ 
The bleeding history of young children who have had no haemostatic challenge may not predict the risk of bleeding in elective surgery. Here, bleeding characteristics and the management of minor surgeries is presented in children and adolescents.

\section{Material and Methods}

This retrospective study was approved by the Ethics and Research Committee of Kocaeli University (KÜ GOKAEK 2019/45). Written informed consents of the patients' legal guardians were obtained during diagnosis for use of patient data in scientific publications.

The hospital records of the patients with RBDs diagnosed and followed up between 1999 and 2018 were evaluated. Patient age at diagnosis, bleeding characteristics at presentation, medical history, plasma factor levels, management of the bleeding episodes and surgeries were documented.

Diagnosis was based on the bleeding history, bleeding symptoms of the patient, family history, prothrombin time (PT), activated partial-thromboplastin time (APTT), and plasma $\mathrm{F}: \mathrm{C}$ levels. In cases of FVII deficiency, only PT; in FX, FV, Fibrinogen, FV+VIII deficiency both PT and APTT, in FXI deficiency only APTT is expected to be prolonged. All of the coagulation studies were performed in the local laboratory. For fibrinogen $<100 \mathrm{mg} / \mathrm{dl}$ and for FV, FVII, FX, and FXI, $<50 \%$ was considered as a deficiency. ${ }^{7,8}$ Genetic analysis was performed only in the case of one patient with afibrinogenemia.

Clinical bleeding episodes were classified into four severity categories. Asymptomatic patients had no documented bleeding episodes. Grade I bleeding was defined as bleeding after trauma or drug ingestion. Grade II bleeding was defined as spontaneous minor bleeding, such as bruising, ecchymosis, minor wounds, oral cavity bleeding, epistaxis and menorrhagia. Grade III bleeding was defined as spontaneous major bleeding, such as hematomas, hemarthrosis, CNS bleeding, GIS bleeding, and umbilical cord bleeding. ${ }^{3}$
Minor surgery often refers to the surgery which does not have a significant risk of large volume blood loss or blood loss into a confined anatomical space like major abdominal, intracranial, cardiovascular, spinal or major orthopaedic surgeries, that requires hemostatic support less than 5 consecutive days. ${ }^{9,10}$

SPSS version 22 statistical software was used for descriptive analysis. Quantitative data were given as mean \pm standard deviation.

\section{Results}

There were 12 (46.2\%) females and 14 (53.8\%) males. The median age at diagnosis was 7.7 years (8 months- 16.9 years). The mean followup time was 6.9 years (2 months- 16.3 years). The median diagnosis age of the patients with severe bleeding phenotype (Grade III bleeding) was 3 years ( 8 months-16.9 years), and severe factor deficiencies (with plasma F:C activity $<1 \%$ or undetectable) was 3,89 years (8 months- 16.9 years).

FVII deficiency (n:12, 46.2\%) was the most frequent RBD, followed by FXI deficiency (n:6, 23.1\%), afibrinogenemia (n: 4, 15.4\%), FV deficiency (n: 3, 11.5\%), and FV+FVIII deficiency (n:1, 3.8\%). There was consanguinity in $9(34.6 \%)$ patients, and 7 (26.9\%) patients had a family history of bleeding. Molecular analysis could be performed in patient 1 and mutation in FGB gene (FGB exon 4 C/T nt.5330/p.leu 195 pro mutation) was detected.

Four asymptomatic patients $(23.1 \%)$ were diagnosed during preoperative coagulation screening. One patient was screened due to family history and another during a urinary tract infection. According to the bleeding severity, 3 patients (11.5\%) presented grade I bleeding, $11(42.3 \%)$ grade II bleeding, and $6(23.1 \%)$ grade III bleeding. The most common bleeding symptom during follow-up of the patients was epistaxis (n: 11, 42.3\%). Other bleedings were gum bleeding (n: 7, 26.9\%), ecchymosis (n: 6, $23.1 \%$ ), menorrhagia (n: $6,50 \%$ of the adolescent girls), hemarthrosis (n: 4, 15.4\%), hematuria (n: 
1, 3.8\%), postoperative bleeding (n: $1,3.8 \%$ ), intraabdominal bleeding (n: 1, 3.8\%), CNS bleeding (n: 1, 3.8\%), spontaneous splenic rupture (n: $1,3.8 \%)$, and soft tissue hematoma (n: 1, 3.8\%) (Table I).

Life-threatening bleedings were observed only in the patients with afibrinogenemia. Patient 1, Patient 2 and patent 4 with afibrinogenemia presented with grade III bleeding including spontaneous spleen rupture, intraabdominal bleeding and CNS bleeding respectively and good hemostatic control was provided with pd-fibrinogen concentrate. Patient 2 with afibrinogenemia had a sibling who died due to intracranial bleeding following trauma.

Prophylaxis with $30 \mathrm{mg} / \mathrm{kg}$ pd-fibrinogen weekly was administered only to patient 4 with afibrinogenemia, following spontaneous CNS bleeding.

As single factor concentrates, only rFVIIa and pd-fibrinogen were available in Turkey for our RBD patients with FVII deficiency and afibrinogenemia. The bleeding episodes of the 7 patients with FVII deficiency was controlled with rFVIIa. FFP and/or TXA were used for the bleeding episodes of the other patients. Bleeding episodes of the 3 patients with afibrinogenemia, one patient with FV deficiency and one patient with FVII deficiency required also packed red cell transfusions (Table I).

Seventeen minor surgical interventions were performed in 12 patients; 7 (41.2\%) were tooth extractions, 7 (41.2\%) were circumcisions, one (5.9\%) was hernioplasty, one (5.9\%) was pilonidal sinus operation and one $(5.9 \%)$ was adenotonsillectomy. Seven operations (circumcisions, tooth extractions, pilonidal sinus operation and adeno-tonsillectomy) were performed before factor deficiency was diagnosed. In these surgeries performed without any replacement treatment, hemostasis was good except adenotonsillectomy operation (patient 23). In the elective surgeries performed after diagnosis of RBDs, preoperative rFVIIa, pd-fibrinogen or FFP replacement plus antifibrinolytic treatment for 5-7 days were started even if plasma $\mathrm{F}: \mathrm{C}$ activity was $20-50 \%$. Hemostatic control was good in all patients, and the replacement treatment was not continued after the surgeries in any of the patients. Management of minor surgical procedures is shown in Table II.

\section{Discussion}

This is a single-center study presenting 26 patients with RBDs, but a lengthy followup period gives useful data about bleeding characteristics. Seventeen minor surgical interventions in 12 of the patients were also presented. Similar to other reports from Turkey and the European network of RBDs, the most common disorder was FVII and FXI deficiency, followed by FV, FX, fibrinogen and FXIII deficiencies. FV+FVIII was rarely observed. ${ }^{11-13}$

As expected, in the present study, mucosal bleeding was common. Of the female adolescents, 50\% suffered from menorrhagia. Hemarthrosis was observed in fibrinogen, FV, and FV+VIII deficiency.

Three of the four patients with afibrinogenemia had life-threatening bleeding. They suffered from subdural hematoma, intraabdominal bleeding, and severe scalp bleeding episode after minor traumas. Patient 1 even reported no trauma history on admission to the emergency unit with severe anemia and spleen rupture. The risk of splenic rupture is known to be high in congenital afibrinogenemia patients. ${ }^{14}$ In the literature there are reported patients who have undergone splenectomy due to splenic rupture. ${ }^{14-16}$ In our patient, because the diagnosis was known, splenectomy was not required as a result of rapid intervention with pd-fibrinogen concentrate.

These patients also required packed red cell transfusions. Pd-fibrinogen concentrate replacement and packed red cell transfusions were administered in the first 30 minutes before any imaging study and splenic rupture could be managed successfully. In the European Network of Rare Bleeding Disorders 


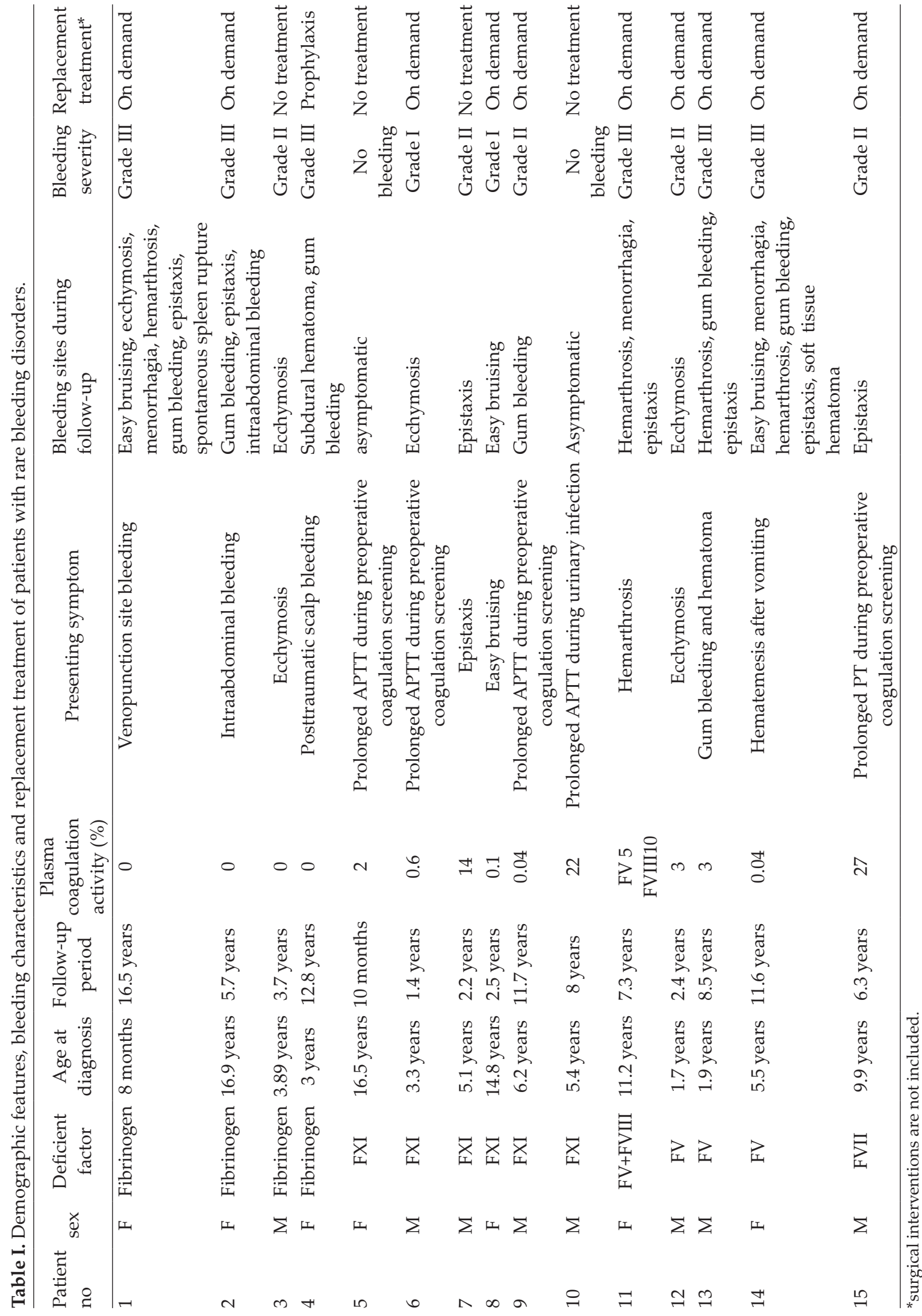




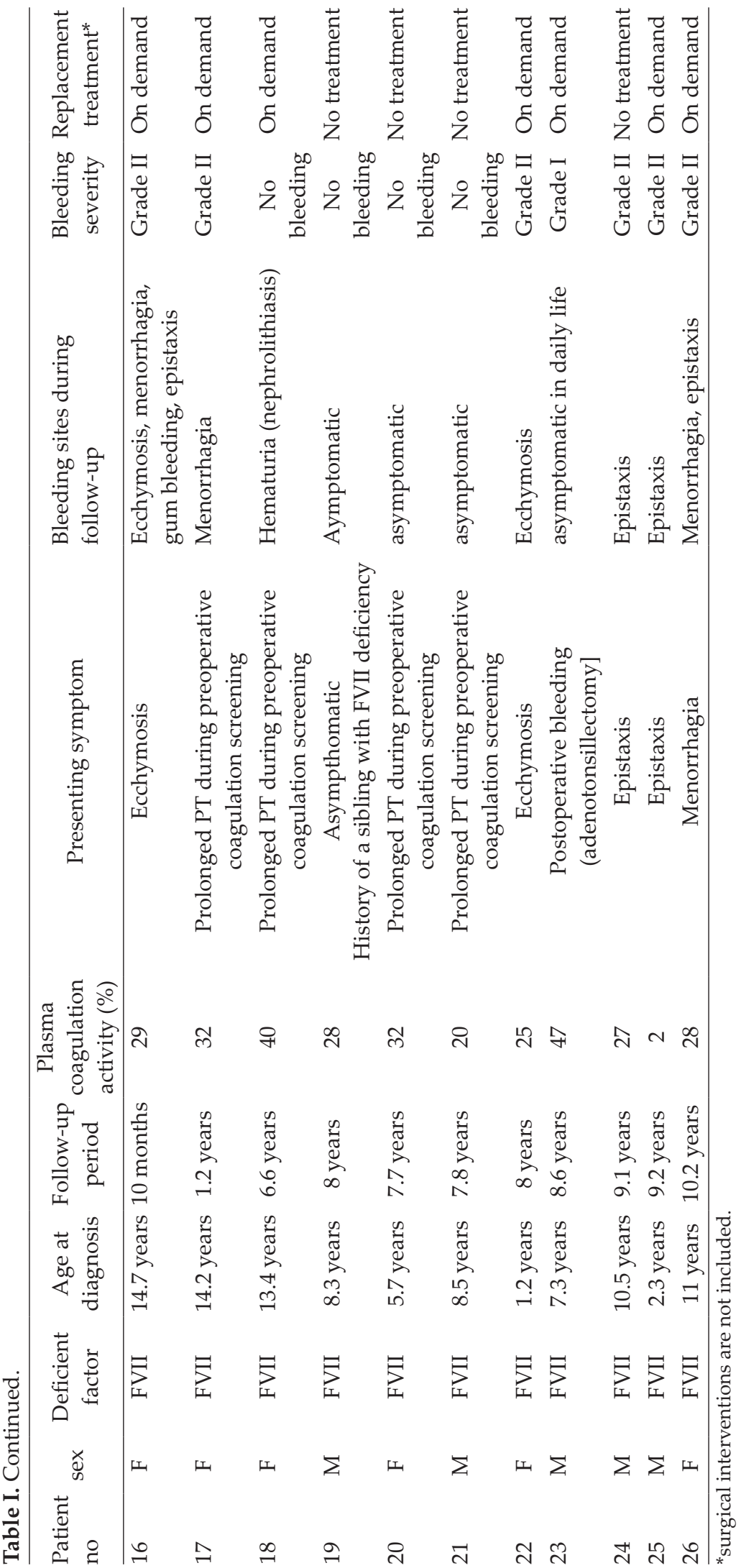




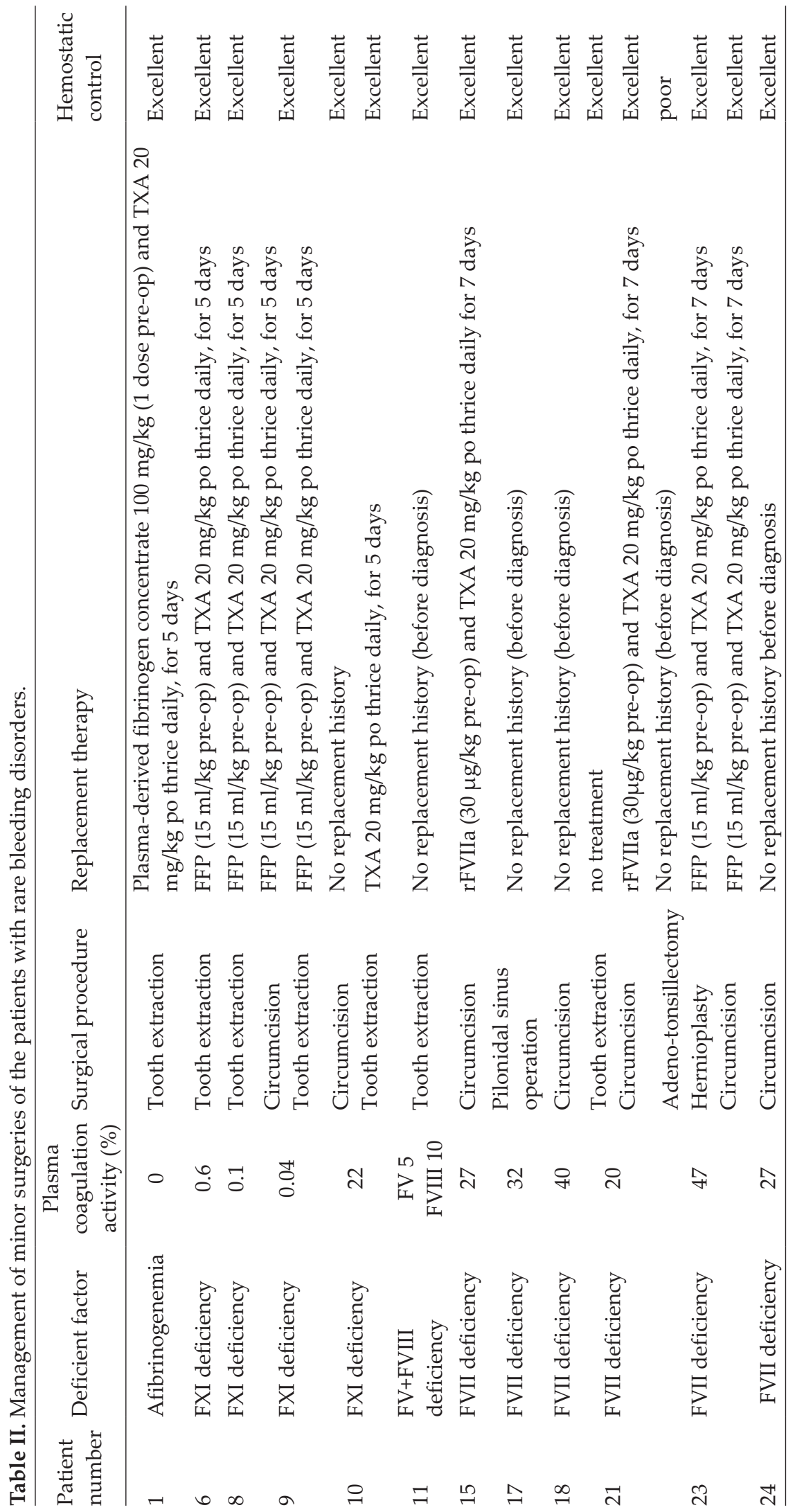


study it is reported that $42.3 \%$ patients with afibrinogenemia and hypofibrinogenemia had a Grade III bleeding history. A strong association is reported between fibrinogen activity level and clinical bleeding severity. ${ }^{17}$ As in Patient 4, prophylaxis with pd-fibrinogen concentrate is recommended in patients with a history of lifethreatening bleeding, especially after central nervous system bleeding. ${ }^{18}$

The patient with FV+FVIII deficiency presented with hemarthrosis after trauma and also had epistaxis and menorrhagia episodes. Replacement with FVIII concentrate plus FFP is recommended but we could achieve hemostasis with FFP or TXA. ${ }^{5}$

The plasma F:C activity of six patients with FXI deficiency was $0.1-22 \%$. Two were asymptomatic (F:C activity 2\% and 22\%) during diagnosis, whereas the others were mild mucosal bleeders. It is reported that there is a weak correlation between bleeding phenotype and F:C activity in FXI deficiency. ${ }^{3}$ Despite F:C activity $<1 \%$ in $3 \mathrm{FXI}$ deficient patients, none of them had severe bleeding phenotype consistent with the literature.

In the present study, three patients showed FV deficiency with factor levels 3\%, 3\%, and $0.4 \%$, respectively. In addition to the mucosal bleeding, these patients suffered from soft tissue hematoma and hemarthrosis. All bleeding episodes were successfully treated with FFP and TXA. Life-threatening bleeding episodes are very rare in FV deficiency..$^{19}$ None of our FV deficient patients experienced life-threatening bleedings.

Clinical findings of FVII deficiency were reported to be heterogeneous, ranging from asymptomatic patients to patients with serious and fatal bleeding. ${ }^{720}$ Some polymorphisms were described within human F7 gene that affect both plasma FVII:C levels and plasma VII antigen levels. Patients with F:C level near to $50 \%$ may be carriers of these polymorphisms. ${ }^{21}$ In the present study 5 of the 12 patients with FVII deficiency were diagnosed due to prolonged
PT during preoperative coagulation screening. Another asymptomatic patient (Patient 19) with F:C activity $28 \%$ was diagnosed due to family history. Similar to the literature, the most frequent symptoms were epistaxis and menorrhagia. ${ }^{20}$ Half of the female adolescents had menorrhagia, and one of them was treated with both rFVIIa and FFP plus TXA, and even required packed red cell transfusion.

Consistent with our patients, it is reported that, in FV, FVII and FXI deficiencies there is a weak correlation between the bleeding severity and $\mathrm{F}: \mathrm{C}$ level..$^{3,8,20}$

Packed red cell transfusion was required in 10$20 \%$ of patients with RBDs. ${ }^{2}$ In the present study, packed red cell transfusion was administered to $19.2 \%$ of the patients during bleeding episodes.

A fibrinogen plasma level of $1-1.5 \mathrm{~g} / \mathrm{L}$ is recommended for minor surgery; this level may be achieved by a $50-100 \mathrm{mg} / \mathrm{kg}$ dose. Due to long half-life, this dose may be repeated at 2-4 day intervals when required. For minor surgery, TXA $15-20 \mathrm{mg} / \mathrm{kg}$ may be sufficient. ${ }^{22}$ In a phase III trial of pd-fibrinogen concentrate, three minor surgeries (radioisotope synovectomy, dental extraction, circumcision) were planned. Plasma preoperative fibrinogen levels of 100 $\mathrm{mg} / \mathrm{dl}$ were achieved with a median $70.0(65.8-$ 102.6) $\mathrm{mg} / \mathrm{kg}$ infusion and excellent hemostasis was achieved..$^{23}$ In our study, only one patient with afibrinogenemia had a minor operation (Patient 1, tooth extraction), and the procedure was without bleeding complication under preoperative one dose $100 \mathrm{mg} / \mathrm{kg}$ pd-fibrinogen concentrate plus TXA therapy and did not required any repeated dose.

In a post-marketing study of recombinant FXIa in bleeding episodes, surgery, and invasive procedures, the median infusion dose per episode was $18.0 \mathrm{U} / \mathrm{kg}$ (mean 18.7) and the median number of infusions per episode was 1.0. Hemostatic control was satisfactory. ${ }^{24}$ Two of the patients with FXI deficiency (Patients 9 and 10) underwent circumcision with excellent hemostasis (one without any replacement; the 
other with FFP and TXA administration). Four tooth extractions were performed with FFP and/ or TXA with good hemostatic control. We used FFP instead of recombinant FXI concentrate, because it is not available in Turkey.

Some reports have shown that in patients with factor V plasma F:C activity 14.1 to $22.4 \%$, single uncomplicated tooth extractions can be managed safely without replacement therapy. Mouth rinse with tranexamic acid, nonresorbable sutures, and a gelatin sponge provided satisfactory results. ${ }^{25}$ None of the FV-deficient patients underwent any surgical procedure in the present study.

In the present study, a seven-year-old, FVII deficient patient with F:C activity of $47 \%$ had postoperative bleeding following adenotonsillectomy. He had no bleeding history. Hernioplasty and circumcision were managed successfully with FFP replacement. In this series patients' F:C activity were between 20$47 \%$. Some minor operations could be managed without replacement treatment similar to the literature. Two patients with plasma FVII coagulation levels $0.6 \%$ and $7 \%$ were reported with an uneventful tooth extraction with only antifibrinolytic administration. ${ }^{26}$ Surgical bleeding is reported in about one third of the cases with FVII deficiency. ${ }^{27,28}$ Although evidence is slight, for the minor surgery TXA $15-20 \mathrm{mg} / \mathrm{kg}$ was sufficient. ${ }^{8}$ Some authors suggest that the replacement with only rFVIIa on the day of surgery may be safe in both severe and mild cases due to accumulation of the hemostatically active factor within the extra-vascular space. ${ }^{29,30}$ In the STER study also, in oral surgery, the replacement therapy was given only on the day of the operation and good hemostasis was achieved. Concomitant medication was antifibrinolytics. In the STER study, all enrolled patients had FVII coagulant activity levels of $\leq 20 \%$ of normal. ${ }^{31}$ In this series also to be safe, pre-operative replacement therapy was administered to patient 21 before circumcision although he was asymptomatic. In a study aiming to explore the relationship between F:C activity level and the clinical bleeding severity, it was shown that $\mathrm{F}$ : $\mathrm{C}$ activity levels that were necessary for patients to remain asymptomatic were: fibrinogen $>100 \mathrm{mg} \mathrm{dl}, \mathrm{FV}$ $12 \mathrm{U}$ dl, combined FV + VIII $43 \mathrm{U}$ dl, FVII $25 \mathrm{U}$ dl, FX $56 \mathrm{U}$ dl, FXI $26 \mathrm{U}$ dl and FXIII $31 \mathrm{U}$ dl. ${ }^{11}$

Due to the absence of any correlation between plasma $\mathrm{F}: \mathrm{C}$ activity and surgical bleeding in FV, FVII and FXI deficiency ${ }^{3,8,11,20}$; we suggest that for the safety of the patients, preoperative replacement treatment should be given regardless of the plasma $\mathrm{F}: \mathrm{C}$ activity in these patients.

In this series a patient with FV+VIII deficiency had a history of uneventful tooth extraction without any replacement therapy. In the treatment of the bleeding episodes and surgery replacement treatment with FFP, rFVIIIa and desmopressin is recommended. ${ }^{31,32}$

FFP is a blood component that is easily available and relatively cheap. But there is still a risk of blood-borne infections, volume overload, and transfusion related acute lung injury.

Due to the rarity of RBDs and the heterogeneity of the clinical presentationsthe treatment during bleeding episodes and the management of the surgical interventions can be challenging for physicians. Some minor surgeries can be managed even without replacement therapy. The minor surgeries of RBDs can be managed safely with FFP or FVIIa or pd-fibrinogen concentrate, in addition to TXA. F:C activity of about $15-20 \%$ is safe for minor surgery.

\section{REFERENCES}

1. Peyvandi F, Palla R, Menegatti M, Mannucci PM. Introduction. Rare bleeding disorders: general aspects of clinical features, diagnosis, and management. Semin Thromb Hemost 2009; 35: 349355.

2. Acharya SS, Coughlin A, Dimichele DM; North American Rare Bleeding Disorder Study Group. Rare Bleeding Disorder Registry: deficiencies of factors II, V, VII, X, XIII, fibrinogen and dysfibrinogenemias. J Thromb Haemost 2004; 2: 248-256. 
3. Palla R, Peyvandi F, Shapiro AD. Rare bleeding disorders: diagnosis and treatment. Blood 2015; 125: 2052-2061.

4. Palla R, Siboni SM, Menegatti M, Musallam KM, Peyvandi F; European Network of Rare Bleeding Disorders (EN-RBD) Group. Establishment of a bleeding score as a diagnostic tool for patients with rare bleeding disorders. Thromb Res 2016; 148: 128134.

5. Bolton-Maggs PH, Perry DJ, Chalmers EA, et al. The rare coagulation disorders--review with guidelines for management from the United Kingdom Haemophilia Centre Doctors' Organisation. Haemophilia 2004; 10: 593-628.

6. Jain S, Acharya SS. Management of rare coagulation disorders in 2018. Transfus Apher Sci 2018; 57: 705712 .

7. Peyvandi F, Menegatti M, Palla R. Rare bleeding disorders: worldwide efforts for classification, diagnosis, and management. Semin Thromb Hemost 2013; 39: 579-584.

8. Peyvandi F, Menegatti M. Treatment of rare factor deficiencies in 2016. Hematology Am Soc Hematol Educ Program 2016; ; 2016: 663-669.

9. The Australian Haemophilia Centre Directors' Organisation (AHCDO), and the National Blood Authority, Australia. Guidelines for the Management of Haemophilia in Australia. Malvern East: Victoria, 2016.

10. Srivastava A, Brewer AK, Mauser-Bunschoten EP, et al; Treatment Guidelines Working Group on Behalf of The World Federation of Hemophilia. Guidelines for the management of hemophilia. Haemophilia 2013; 19: e1-e47.

11. Peyvandi F, Palla R, Menegatti M, et al; European Network of Rare Bleeding Disorders Group. Coagulation factor activity and clinical bleeding severity in rare bleeding disorders: results from the European Network of Rare Bleeding Disorders. J Thromb Haemost 2012; 10: 615-621.

12. Tugcu D, Salcioglu Z, Akcay, A et al. How do we encounter rare factor deficiencies in children? Single-center results fromTurkey. Blood Coagul Fibrinolysis 2015; 26: 145-151.

13. Fişgın T, Balkan C, Celkan T, et al. Rare coagulation disorders: a retrospective analysis of 156 patients in Turkey. Turk J Haematol 2012; 29: 48-54.

14. Ehmann WC, al-Mondhiry H. Congenital afibrinogenemia and splenic rupture. Am J Med 1994; 96: 92-94.
15. Akcakus M, Patiroglu T, Keskin M, Koklu E, Gozukucuk A. Nonketotic hyperosmolar coma associated with splenic rupture in congenital afibrinogenemia. J Pediatr Hematol Oncol 2004; 26: 668-671.

16. Arcagök BC, Özdemir N, Tekin A, et al. Spontaneous splenic rupture in a patient with congenital afibrinogenemia. Turk Pediatri Ars 2014; 49: 247-249.

17. Lak M, Keihani M, Elahi F, Peyvandi F, Mannucci PM. Bleeding and thrombosis in 55 patients with inherited afibrinogenaemia. Br J Haematol 1999; 107: 204-206.

18. Franchini M, Marano G, Pupella S, et al. Rare congenital bleeding disorders. Ann Transl Med 2018; 6: 331.

19. Asselta R, Peyvandi F. Factor V deficiency. Semin Thromb Hemost 2009; 35: 382-389.

20. Mariani G, Bernardi F. Factor VII deficiency. Semin Thromb Hemost 2009; 35: 400-406.

21. Perry DJ. Factor VII deficiency. Br J Haematol 2002; 118: 689-700.

22. Mumford AD, Ackroyd S, Alikhan R, et al; BCSH Committee. Guideline for the diagnosis and management of the rare coagulation disorders: a United Kingdom Haemophilia Centre Doctors' Organization guideline on behalf of the British Committee for Standards in Haematology. Br J Haematol 2014; 167: 304-326.

23. Lissitchkov T, Madan B, Djambas Khayat C, et al. Efficacy and safety of a new human fibrinogen concentrate in patients with congenital fibrinogen deficiency: an interim analysis of a Phase III trial. Transfusion 2018; 58: 413-422.

24. Bauduer F, de Raucourt E, Boyer-Neumann $\mathrm{C}$, et al; French Postmarketing Study Group. Factor XI replacement for inherited factor XI deficiency in routine clinical practice: results of the HEMOLEVEN prospective 3-year postmarketing study. Haemophilia 2015; 21: 481-489.

25. Passarelli PC, De Angelis P, Pasquantonio G, Manicone PF, Verdugo F, D'Addona A. Management of single uncomplicated dental extractions and postoperative bleeding evaluation in patients with factor V deficiency: a local antihemorrhagic approach. J Oral Maxillofac Surg 2018; 76: 2280-2283.

26. Kim SH, Park YS, Kwon KH, Lee JH, Kim KC, Yoo MC. Surgery in patients with congenital factor VII deficiency: a single center experience. Korean J Hematol 2012; 47: 281-285. 
27. Mariani G, Dolce A. Congenital factor VII deficiency. In: Lee CA, Berntorp EE, Hoots WK (eds). Textbook of Haemophilia (2nd ed). Malden, MA, USA: Blackwell Publishing, 2005: 313-314.

28. Mariani G, Herrmann FH, Dolce A, et al; International Factor VII Deficiency Study Group. Clinical phenotypes and factor VII genotype in congenital factor VII deficiency. Thromb Haemost 2005; 93: 481-487.

29. Hoffman M, Colina CM, McDonald AG, Arepally GM, Pedersen L, Monroe DM. Tissue factor around dermal vessels has bound factor VII in the absence of injury. J Thromb Haemost 2007; 5: 1403-1408.
30. Mariani G, Dolce A, Batorova A, et al; STER and the International Factor VII Deficiency Study Groups. Recombinant, activated factor VII for surgery in factor VII deficiency: a prospective evaluation - the surgical STER. Br J Haematol 2011; 152: 340-346.

31. Lanchon R, Robin F, Brissaud O, Marro M, NouetteGaulain K. Factor V and VIII combined deficiency: clinical perioperative management for tonsillectomy in a child. Ann Fr Anesth Reanim 2014; 33: e43-e45.

32. Spreafico M, Peyvandi F. Combined FV and FVIII deficiency. Haemophilia 2008; 14: 1201-1208. 